\title{
SIMS analysis of Si isotope for radiolarian test in Mesozoic bedded chert, Inuyama, central Japan
}

\author{
M. BÔLE* ${ }^{* 1}$, M. IKEDA ${ }^{1}$, P.O. BAUMGARTNER ${ }^{2}$, R.S \\ HORI $^{3}$, A.S. BOUVIER ${ }^{2}$ \\ ${ }^{1}$ University of Tokyo, Tokyo 113-0033, Japan. \\ (* correspondence: maximilien.bole@eps.s.u-tokyo.ac.jp, \\ ikeda.masayuki@eps.s.u-tokyo.ac.jp) \\ ${ }^{2}$ University of Lausanne, Lausanne, Switzerland. \\ (Peter.Baumgartner@unil.ch,Anne- \\ Sophie.Bouvier@unil.ch) \\ ${ }^{3}$ Ehime University, Matsuyama, 790-8577, Japan. \\ (hori.rie.mm@ehime-u.ac.jp)
}

The global silica cycle is an important component of the long-term climate system, yet its controlling factors are largely uncertain due to poorly constrained proxy records. Because radiolarians and other organisms preferentially extract lighter ${ }^{28} \mathrm{Si}$ from the ocean, the $\delta^{30} \mathrm{Si}$ of biosiliceous tests can thus be used as a potential proxy of productivity. Additionally, $\delta^{30} \mathrm{Si}$ of oceanic silica could have reflected changes in the isotopic ratio of sources and sinks.

We measured $\delta^{30} \mathrm{Si}$ records by secondary ion mass spectrometer (SIMS) in radiolarian silica, precipitated inside radiolarian molds in early Mesozoic bedded chert of the Inuyama section, central Japan [1]. Range of measured $\delta^{30} \mathrm{Si}$ between -0.3 and $2 \%$ is consistent with that of modern and Cenozoic radiolarian tests. Relatively large intra-chert bed variability up to $\sim 0.8 \%$ (1SD) supports that $\delta^{30} \mathrm{Si}$ of the Mesozoic radiolarian molds are not perfectly homogenized in a chert bed during diagenesis. We found an overall inverse correlation between 10 - Myr scale $\delta^{30} \mathrm{Si}$ and biogenic silica (BSi) burial flux [2], which contradicts with a conventional interpretation of $\delta^{30} \mathrm{Si}$ as paleoproductivity proxy, despite the low-resolution and scattered our $\delta^{30} \mathrm{Si}$ records. Although most of the factors controlling oceanic $\delta^{30} \mathrm{Si}$ are difficult to be constrained, this inverse relation might be explained by changes in weathering rate of highly-weatherable basaltic rock with light $\delta^{30} \mathrm{Si}[1,2]$. Further high-resolution $\delta^{30} \mathrm{Si}$ records will allow a better understanding of the past silica cycle.

[1] Bôle et al. (2020) Bull. Geol. Sur. Japan in press. [2] Ikeda et al. (2017) Nature comm. 15532. 